\title{
REVISED Best practice data life cycle approaches for the life
}

\section{sciences [version 2; peer review: 2 approved]}

\author{
Philippa C. Griffin¹,2, Jyoti Khadake3, Kate S. LeMay (iD), Suzanna E. Lewis5, \\ Sandra Orchard (D6), Andrew Pask7, Bernard Pope (D)2, Ute Roessner ${ }^{8}$, \\ Keith Russell (D) 4, Torsten Seemann², Andrew Treloar ${ }^{4}$, Sonika Tyagi (i)9,10, \\ Jeffrey H. Christiansen ${ }^{11}$, Saravanan Dayalan8, Simon Gladman1, \\ Sandra B. Hangartner ${ }^{12}$, Helen L. Hayden ${ }^{13}$, William W.H. Ho ${ }^{7}$, \\ Gabriel Keeble-Gagnère ${ }^{7,13}$, Pasi K. Korhonen ${ }^{14}$, Peter Neish ${ }^{15}$, \\ Priscilla R. Prestes ${ }^{16}$, Mark F. Richardson (D17, Nathan S. Watson-Haigh ${ }^{18,}$ \\ Kelly L. Wyres ${ }^{19}$, Neil D. Young ${ }^{14}$, Maria Victoria Schneider2,15
}

\footnotetext{
${ }^{1}$ EMBL Australia Bioinformatics Resource, The University of Melbourne, Parkville, VIC, 3010, Australia

${ }^{2}$ Melbourne Bioinformatics, The University of Melbourne, Parkville, VIC, 3010, Australia

${ }^{3}$ NIHR BioResource, University of Cambridge and Cambridge University Hospitals NHS Foundation Trust Hills Road, Cambridge, CB2 OQQ, UK

${ }^{4}$ Australian National Data Service, Monash University, Malvern East, VIC, 3145, Australia

${ }^{5}$ Lawrence Berkeley National Laboratory, Environmental Genomics and Systems Biology Division, Berkeley, CA, 94720, USA

${ }^{6}$ European Bioinformatics Institute (EMBL-EBI), European Molecular Biology Laboratory, Cambridge, CB10 1SD, UK

${ }^{7}$ School of BioSciences, The University of Melbourne, Parkville, VIC, 3010, Australia

${ }^{8}$ Metabolomics Australia, School of BioSciences, The University of Melbourne, Parkville, VIC, 3010, Australia

${ }^{9}$ Australian Genome Research Facility Ltd, Parkville, VIC, 3052, Australia

${ }^{10}$ Monash Bioinformatics Platform, Monash University, Clayton, VIC, 3800, Australia

${ }^{11}$ Queensland Cyber Infrastructure Foundation and the University of Queensland Research Computing Centre, St Lucia, QLD, 4072, Australia

${ }^{12}$ School of Biological Sciences, Monash University, Clayton, VIC, 3800, Australia

${ }^{13}$ Agriculture Victoria, AgriBio, Bundoora, VIC, 3083, Australia

${ }^{14}$ Faculty of Veterinary and Agricultural Sciences, The University of Melbourne, Parkville, VIC, 3010, Australia

15The University of Melbourne, Parkville, VIC, 3010, Australia

${ }^{16}$ Faculty of Science and Engineering, Federation University Australia, Mt Helen, VIC, 3350, Australia

${ }^{17}$ Bioinformatics Core Research Group \& Centre for Integrative Ecology, Deakin University, Geelong, VIC, 3220, Australia

${ }^{18}$ School of Agriculture, Food and Wine, University of Adelaide, Glen Osmond, SA, 5064, Australia

${ }^{19}$ Department of Biochemistry and Molecular Biology, Bio21 Molecular Science and Biotechnology Institute, The University of Melbourne, Parkville, VIC, 3010, Australia
}

\section{V2 First published: 31 Aug 2017, 6:1618 \\ https://doi.org/10.12688/f1000research.12344.1}

Latest published: 04 Jun 2018, 6:1618

https://doi.org/10.12688/f1000research.12344.2

\section{Abstract}

Throughout history, the life sciences have been revolutionised by technological advances; in our era this is manifested by advances in instrumentation for data generation, and consequently researchers now routinely handle large amounts of heterogeneous data in digital

\section{Open Peer Review}

Approval Status

1 2

version 2

(revision)

04 Jun 2018 
formats. The simultaneous transitions towards biology as a data science and towards a 'life cycle' view of research data pose new challenges. Researchers face a bewildering landscape of data management requirements, recommendations and regulations, without necessarily being able to access data management training or possessing a clear understanding of practical approaches that can assist in data management in their particular research domain.

Here we provide an overview of best practice data life cycle approaches for researchers in the life sciences/bioinformatics space with a particular focus on 'omics' datasets and computer-based data processing and analysis. We discuss the different stages of the data life cycle and provide practical suggestions for useful tools and resources to improve data management practices.

\section{Keywords} data sharing, data management, open science, bioinformatics, reproducibility

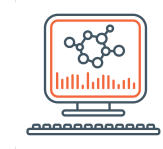

This article is included in the Bioinformatics gateway.

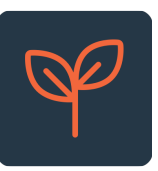

This article is included in the Agriculture, Food and Nutrition gateway.

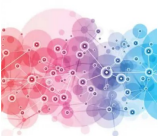

This article is included in the Research on Research, Policy \& Culture gateway.

EMBL-EBI :

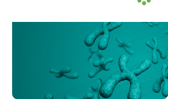

This article is included in the EMBL-EBI

collection. 
Corresponding authors: Philippa C. Griffin (pip.griffin@gmail.com), Maria Victoria Schneider (mvschneiderg@gmail.com)

Author roles: Griffin PC: Conceptualization, Visualization, Writing - Original Draft Preparation, Writing - Review \& Editing; Khadake J: Writing - Review \& Editing; LeMay KS: Writing - Review \& Editing; Lewis SE: Writing - Review \& Editing; Orchard S: Writing - Review \& Editing; Pask A: Writing - Review \& Editing; Pope B: Writing - Review \& Editing; Roessner U: Writing - Review \& Editing; Russell K: Writing - Review \& Editing; Seemann T: Writing - Review \& Editing; Treloar A: Writing - Review \& Editing; Tyagi S: Writing - Review \& Editing; Christiansen JH: Writing - Review \& Editing; Dayalan S: Writing - Review \& Editing; Gladman S: Writing - Review \& Editing; Hangartner SB: Writing - Review \& Editing; Hayden HL: Writing - Review \& Editing; Ho WWH: Writing - Review \& Editing; KeebleGagnère G: Writing - Review \& Editing; Korhonen PK: Writing - Review \& Editing; Neish P: Writing - Review \& Editing; Prestes PR: Writing - Review \& Editing; Richardson MF: Writing - Review \& Editing; Watson-Haigh NS: Writing - Review \& Editing; Wyres KL: Writing - Review \& Editing; Young ND: Writing - Review \& Editing; Schneider MV: Conceptualization, Supervision, Writing - Original Draft Preparation, Writing - Review \& Editing

Competing interests: No competing interests were disclosed.

Grant information: This publication was possible thanks to funding support from the University of Melbourne and Bioplatforms Australia (BPA) via an Australian Government NCRIS investment (to EMBL-ABR). The funders had no role in study design, data collection and analysis, decision to publish, or preparation of the manuscript.

Copyright: (c) 2018 Griffin PC et al. This is an open access article distributed under the terms of the Creative Commons Attribution License, which permits unrestricted use, distribution, and reproduction in any medium, provided the original work is properly cited. Data associated with the article are available under the terms of the Creative Commons Zero "No rights reserved" data waiver (CC0 1.0 Public domain dedication).

How to cite this article: Griffin PC, Khadake J, LeMay KS et al. Best practice data life cycle approaches for the life sciences [version 2; peer review: 2 approved] F1000Research 2018, 6:1618 https://doi.org/10.12688/f1000research.12344.2

First published: 31 Aug 2017, 6:1618 https://doi.org/10.12688/f1000research.12344.1 


\section{REVISED Amendments from Version 1}

In Version 2 of this article we have addressed the comments of the two reviewers, and included more detail about integrating datasets, workflows, authentication and privacy considerations. We have also included a second figure (Figure 2), a flowchart showing how the data life cycle considerations might be applied to an example research project.

See referee reports

\section{Introduction}

Technological data production capacity is revolutionising biology ${ }^{1}$, but is not necessarily correlated with the ability to efficiently analyse and integrate data, or with enabling longterm data sharing and reuse. There are selfish as well as altruistic benefits to making research data reusable ${ }^{2}$ : it allows one to find and reuse one's own previously-generated data easily; it is associated with higher citation rates ${ }^{3,4}$; and it ensures eligibility for funding from and publication in venues that mandate data sharing, an increasingly common requirement (e.g. Final NIH statement on sharing research data, Wellcome Trust policy on data management and sharing, Bill \& Melinda Gates Foundation open access policy). Currently we are losing data at a rapid rate, with up to $80 \%$ unavailable after 20 years $^{5}$. This affects reproducibility - assessing the robustness of scientific conclusions by ensuring experiments and findings can be reproduced - which underpins the scientific method. Once access to the underlying data is lost, replicability, reproducibility and extensibility ${ }^{6}$ are reduced.

At a broader societal level, the full value of research data may go beyond the initial use case in unforeseen ways ${ }^{7,8}$, so ensuring data quality and reusability is crucial to realising its potential value $\mathrm{e}^{9-12}$. The recent publication of the FAIR principles ${ }^{9,13}$ identifies four key criteria for high-quality research data: the data should be Findable, Accessible, Interoperable and Reusable. Whereas a traditional view of data focuses on collecting, processing, analysing data and publishing results only, a life cycle view reveals the additional importance of finding, storing and sharing data ${ }^{11}$. Throughout this article, we present a researcherfocused data life cycle framework that has commonalities with other published frameworks [e.g. the DataONE Data Life Cycle, the US geological survey science data lifecycle model and ${ }^{11,14-15}$, but is aimed at life science researchers specifically (Figure 1).

Learning how to find, store and share research data is not typically an explicit part of undergraduate or postgraduate training in the biological sciences ${ }^{16-18}$, though some subdomains (e.g. ecology) have a history of data management advice ${ }^{8,19}$. The scope, size and complexity of datasets in many fields has increased dramatically over the last 10-20 years, but the knowledge of how to manage this data is currently limited to specific cohorts of 'information managers' (e.g. research data managers, research librarians, database curators and IT professionals with expertise in databases and data schemas ${ }^{18}$ ). In response to institutional and funding requirements around data availability, a number of tools and educational programs have been

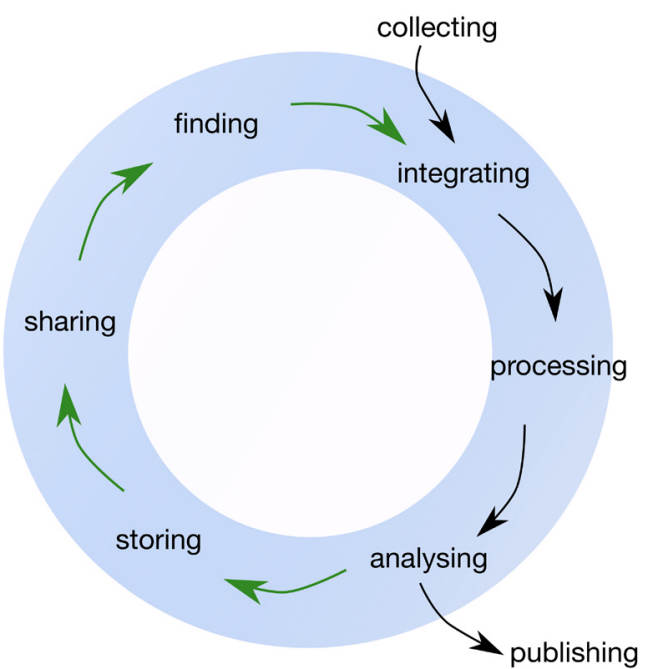

Figure 1. The Data Life Cycle framework for bioscience, biomedical and bioinformatics data that is discussed throughout this article. Black arrows indicate the 'traditional', linear view of research data; the green arrows show the steps necessary for data reusability. This framework is likely to be a simplified representation of any given research project, and in practice there would be numerous 'feedback loops' and revisiting of previous stages. In addition, the publishing stage can occur at several points in the data life cycle.

developed to help researchers create Data Management Plans to address elements of the data lifecycle ${ }^{20}$; however, even when a plan is mandated, there is often a gap between the plan and the actions of the researcher ${ }^{10}$.

This publication targets life science researchers wanting to improve their data management practice but will also be relevant to life science journals, funders, and research infrastructure bodies. It arose from a 2016 workshop series on the data lifecycle for life science researchers run by EMBL Australia Bioinformatics Resource ${ }^{21}$, which provided opportunities to (i) map the current approaches to the data life cycle in biology and bioinformatics, and (ii) present and discuss best practice approaches and standards for key international projects with Australian life scientists and bioinformaticians. Throughout the article we highlight some specific data management challenges mentioned by participants. An earlier version of this article can be found on bioRxiv (https://doi.org/10.1101/167619).

\section{Finding data}

In biology, research data is frequently published as supplementary material to articles, on personal or institutional websites, or in non-discipline-specific repositories like Figshare and Dryad ${ }^{22}$. In such cases, data may exist behind a paywall, there is no guarantee it will remain extant, and, unless one already knows it exists and its exact location, it may remain undiscovered ${ }^{23}$. It is only when a dataset is added to a public data repository, along with accompanying standardized descriptive metadata (see Collecting data), that it can be indexed and made publicly available ${ }^{24}$. Data repositories also provide unique identifiers 
that increase findability by enabling persistent linking from other locations and permanent association between data and its metadata.

In the field of molecular biology, a number of bioinformaticsrelevant organisations host public data repositories. National and international-level organisations of this kind include the European Bioinformatics Institute (EMBL-EBI) ${ }^{25}$, the National Centre for Biotechnology Information $(\mathrm{NCBI})^{26}$, the DNA Data Bank of Japan (DDBJ) $)^{27}$, the Swiss Institute of Bioinformatics $(\mathrm{SIB})^{28}$, and the four data center members of the worldwide Protein Data Bank $^{29}$, which mirror their shared data with regular, frequent updates. This shared central infrastructure is hugely valuable to research and development. For example, EMBL-EBI resources have been valued at over $£ 270$ million per year and contribute to $\sim £ 1$ billion in research efficiencies; a 20 -fold return on investment ${ }^{30}$.

Numerous repositories are available for biological data (see Table 1 for an overview), though repositories are still lacking for some data types and sub-domains ${ }^{31}$. Due to privacy regulations, human data is generally not freely available and these repositories typically require access requests on an individual dataset basis ${ }^{32,33}$. Tools like the dbGAP browser ${ }^{34}$ and the Beacon Network $^{35}$ can assist in identifying relevant limited-access datasets and reduce the burden associated with requesting and downloading data.

Many specialised data repositories exist outside of the shared central infrastructure mentioned, often run voluntarily or with minimal funding. Support for biocuration, hosting and maintenance of these smaller-scale but key resources is a pressing problem $^{36-38}$. The quality of the user-submitted data in public repositories $^{39,40}$ can mean that public datasets require extra curation before reuse. Unfortunately, due to low uptake of established methods (see the EMBL-EBI and NCBI third-party annotation policies; ${ }^{41}$ ) to correct the data ${ }^{40}$, the results of extra curation may not find their way back into the repositories. Repositories are often not easily searched by generic web search engines ${ }^{31}$. Registries, which form a secondary layer linking multiple, primary repositories, may offer a more convenient way to search across multiple repositories for data relevant to a researcher's topics of interest ${ }^{42}$.

\section{Collecting data}

The most useful data has associated information about its creation, its content and its context - called metadata. If metadata is well structured, uses consistent element names and contains element values with specific descriptions from agreedupon vocabularies, it enables machine readability, aggregation, integration and tracking across datasets: allowing for Findability, Interoperability and Reusability ${ }^{9,31}$. One key approach in bestpractice metadata collection is to use controlled vocabularies built from ontology terms. Biological ontologies are tools that provide machine-interpretable representations of some aspect of biological reality ${ }^{31,43}$. They are a way of organising and defining objects (i.e. physical entities or processes), and the relationships between them. Sourcing metadata element values from ontologies ensures that the terms used in metadata are consistent and clearly defined. There are several user-friendly tools available to assist researchers in accessing, using and contributing to ontologies (Table 2).

Adopting standard data and metadata formats and syntax is critical for compliance with FAIR principles ${ }^{9,24,31,42,44}$. Biological and biomedical research has been considered an especially challenging research field in this regard, as datatypes are extremely heterogeneous and not all have defined data standards ${ }^{44,45}$; many existing data standards are complex and therefore difficult to $u^{4} e^{45}$, or only informally defined, and therefore subject to variation, misrepresentation, and divergence over time ${ }^{44}$. Nevertheless, well-established standards exist for a variety of biological data types (Table 3). FAIRsharing is a useful registry of data standards and policies that also indicates the current status of standards for different data types and those recommended by databases and research organisations ${ }^{42}$.

Most public repositories for biological data (see Table 1 and Storing data section) require that minimum metadata be submitted accompanying each dataset (Table 4). This minimum metadata specification typically has broad community input ${ }^{46}$. Minimum metadata standards may not include the crucial metadata fields that give the full context of the particular research project $^{46}$, so it is important to gather metadata early, understand how to extend a minimum metadata template to include additional fields in a structured way, and think carefully about all the relevant pieces of metadata information that might be required for reuse.

\section{Integrating, processing and analysing data}

Where existing and/or newly-collected datasets are to be used in the same experiment, they must first be integrated. This may involve initial processing of one or more datasets so that they share format and granularity, or so that relevant fields map correctly. The researcher also needs to ensure integration at 'dependency' level: for example, controlled vocabularies or genome assemblies used in data generation/processing must match or be easily converted. The plethora of autonomous data repositories has created problems with mapping data and annotations among repositories ${ }^{47,48}$. Current largescale efforts aim to improve interoperability using Linked Data and other Semantic Web tools ${ }^{48}$ as well as extensive ontology development (see Collecting data section). The Monarch Initiative is an example of a project that achieves new insights by integrating existing data from multiple sources: in this case, data from animal and human genetic, phenotypic and other repositories is brought together via a custom data flow to help identify unrecognised animal models for human disease $^{49}$. In smaller projects, the need for individual researchers to integrate data will often inform the way new data is collected, to ensure it matches existing datasets, creating a feedback loop in the data lifecycle that highlights the need for prior planning (Figure 2). Seamless solutions are still some way off $^{50}$ for all but a handful of applications.

Recording and reporting how research data is processed and analysed computationally is crucial for reproducibility and assessment of research quality ${ }^{1,51}$. This can be aided by 


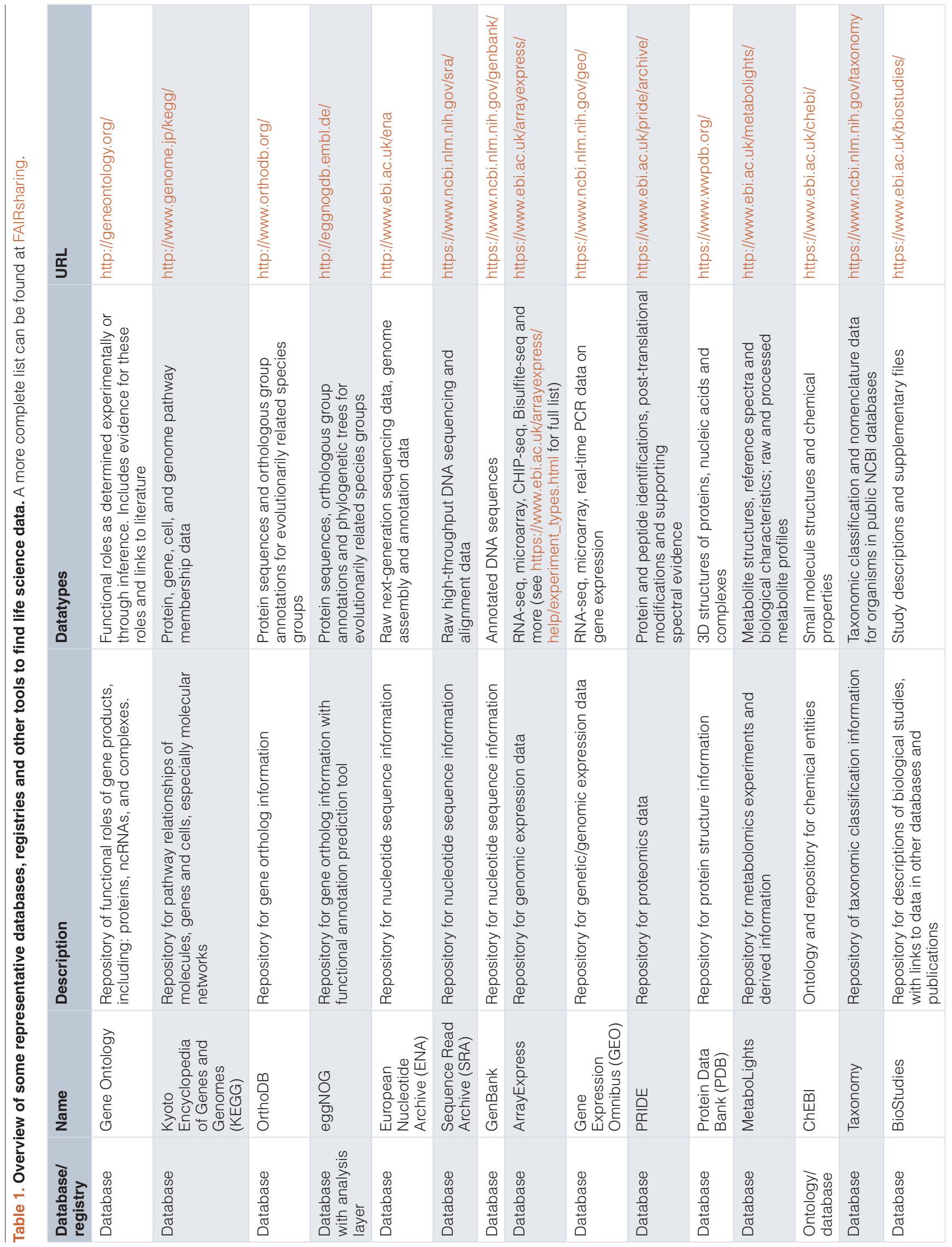




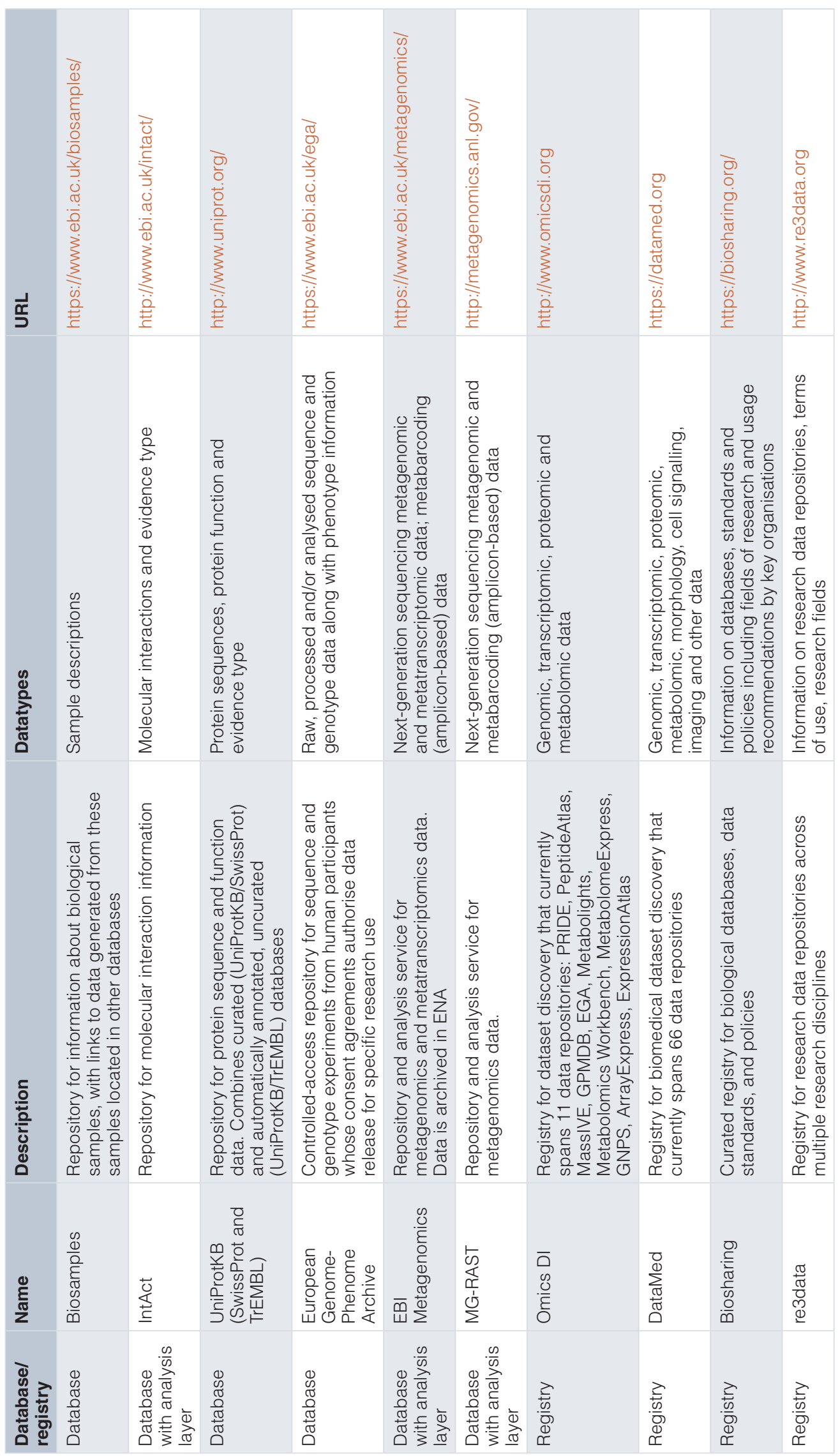




\section{Table 2. Useful ontology tools to assist in metadata collection.}

\begin{tabular}{|c|c|c|}
\hline Tool & Task & URL \\
\hline $\begin{array}{l}\text { Ontology Lookup } \\
\text { Service }\end{array}$ & Discover different ontologies and their contents & http://www.ebi.ac.uk/ols/ \\
\hline OBO Foundry & $\begin{array}{l}\text { Table of open biomedical ontologies with information } \\
\text { on development status, license and content }\end{array}$ & http://obofoundry.org/ \\
\hline Zooma & Assign ontology terms using curated mapping & http://www.ebi.ac.uk/spot/zooma/ \\
\hline Webulous & Create new ontology terms easily & https://www.ebi.ac.uk/efo/webulous/ \\
\hline Ontobee & $\begin{array}{l}\text { A linked data server that facilitates ontology data } \\
\text { sharing, visualization, and use. }\end{array}$ & http://www.ontobee.org \\
\hline
\end{tabular}

scientific workflow approaches that facilitate both recording and reproducing processing and analysis steps ${ }^{1}$, though many experiments will require 'one-off' workflows that may not function with existing workflow management systems. Full reproducibility requires access to the software, software versions, workflow, dependencies and operating system used as well as the data and software code itself $f^{1,52}$. Therefore, although computational work is often seen as enabling reproducibility in the short term, in the long term it is fragile and reproducibility is limited (e.g. discussion by D. Katz, K. Hinsen and C.T. Brown). Best-practice approaches for preserving data processing and analysis code involve hosting source code in a repository where it receives a unique identifier and is under version control; where it is open, accessible, interoperable and reusable - broadly mapping to the FAIR principles for data. Github and Bitbucket, for example, fulfil these criteria, and Zenodo additionally generates Digital Object Identifiers (DOIs) for submissions and guarantees long-term archiving. Workflows can also be preserved in repositories along with relevant annotations (reviewed in 1). A complementary approach is containerised computing (e.g. Docker) which bundles operating system, software, code and potentially workflows and data together. Several recent publications have suggested ways to improve current practice in research software development to aid in reproducibility ${ }^{15,53-55}$.

The same points hold for wet-lab data production: for full reproducibility within and outside the lab, it is important to capture and enable access to specimen cell lines, tissue samples and/or DNA as well as reagents ${ }^{56}$. Wet-lab methods can be captured in electronic laboratory notebooks and reported in the Biosamples database ${ }^{57}$, protocols.io or OpenWetWare; specimens can be lodged in biobanks, culture or museum collections ${ }^{58-62}$; but the effort involved in enabling full reproducibility remains extensive. Electronic laboratory notebooks are frequently suggested as a sensible way to make this information openly available and archived $^{63}$. Some partial solutions exist (e.g. LabTrove, BlogMyData, Benchling and others ${ }^{64}$ ), including tools for specific domains such as the Scratchpad Virtual Research Environment for natural history research ${ }^{65}$. Other tools can act as or be combined to produce notebooks for small standalone code-based projects (see 66 and update), including Jupyter Notebook, Rmarkdown, and Docker. However, it remains a challenge to implement online laboratory notebooks to cover both field/lab work and computer-based work, especially when computer work is extensive, involved and non-modular ${ }^{51}$. Currently, no best-practice guidelines or minimum information standards exist for use of electronic laboratory notebooks ${ }^{6}$. We suggest that appropriate minimum information to be recorded for most computer-based tasks should include date, task name and brief description, aim, actual command(s) used, software names and versions used, input/output file names and locations, script names and locations, all in a simple text format.

In the authors' experience, the data processing and analysis stage is one of the most challenging for openness. As reported elsewhere ${ }^{16-18}$, we have observed a gap between modern biological research as a field of data science, and biology as it is still mostly taught in undergraduate courses, with little or no focus on computational analysis, or project or data management. This gap has left researchers lacking key knowledge and skills required to implement best practices in dealing with the life cycle of their data.

\section{Publishing data}

Traditionally, scientific publications included raw research data, but in recent times datasets have grown beyond the scope of practical inclusion in a manuscript $t^{11,51}$. Selected data outputs are often included without sharing or publishing the underlying raw data ${ }^{14}$. Journals increasingly recommend or require deposition of raw data in a public repository [e.g. 67], although exceptions have been made for publications containing commercially-relevant data $^{68}$. The current data-sharing mandate is somewhat field-dependent ${ }^{5,69}$ and also varies within fields ${ }^{70}$. For example, in the field of bioinformatics, the UPSIDE principle $^{71}$ is referred to by some journals (e.g. Bioinformatics), while others have journal- or publisher-specific policies (e.g. BMC Bioinformatics).

The vast majority of scientific journals require inclusion of processing and analysis methods in 'sufficient detail for reproduction' (e.g. Public Library of Science submission and data availability guidelines; International Committee of Medical Journal Editors manuscript preparation guidelines; Science instructions for authors; Elsevier Cell Press STAR Methods; and $d^{72}$ ), though journal requirements are diverse and complex ${ }^{73}$, 


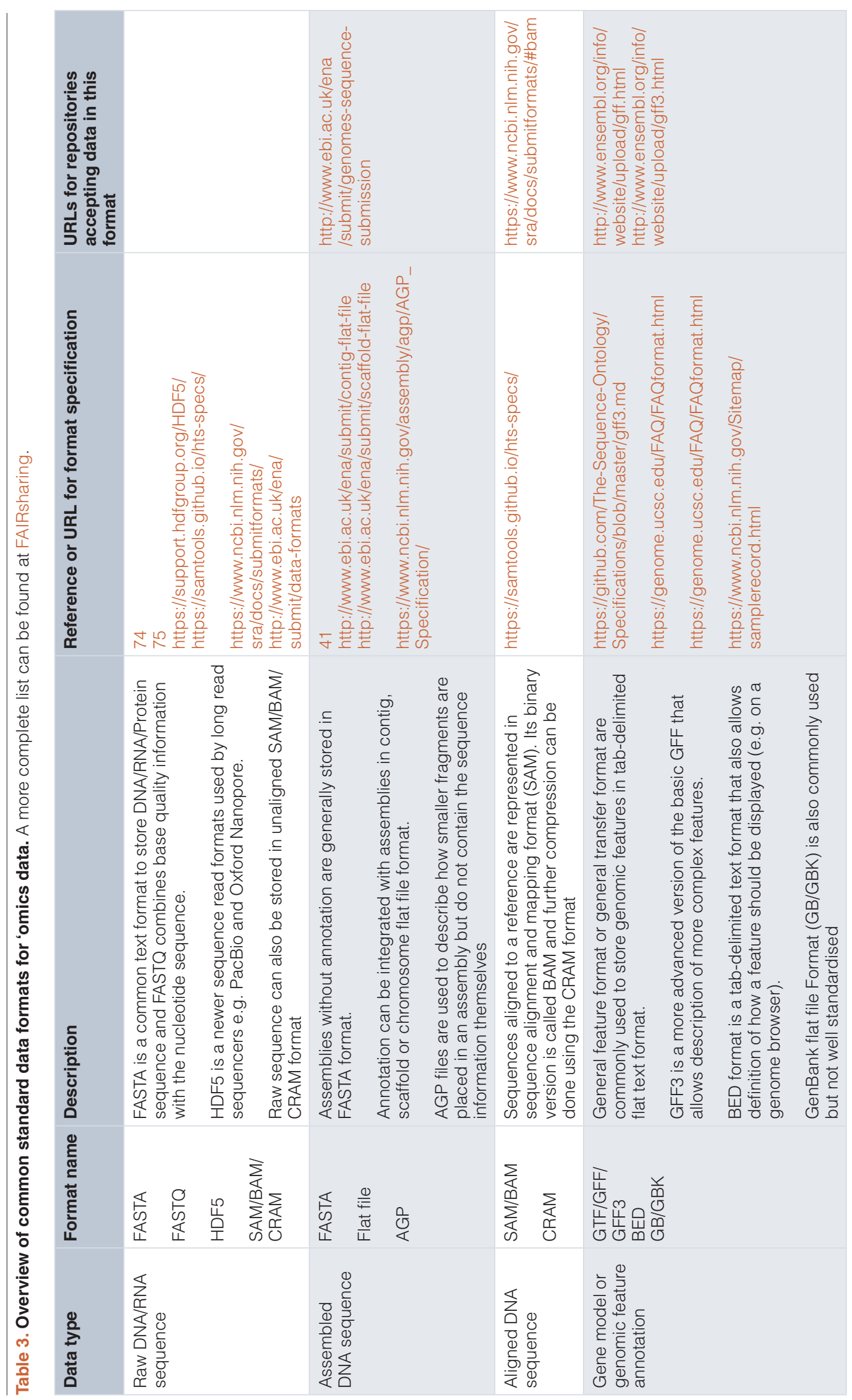




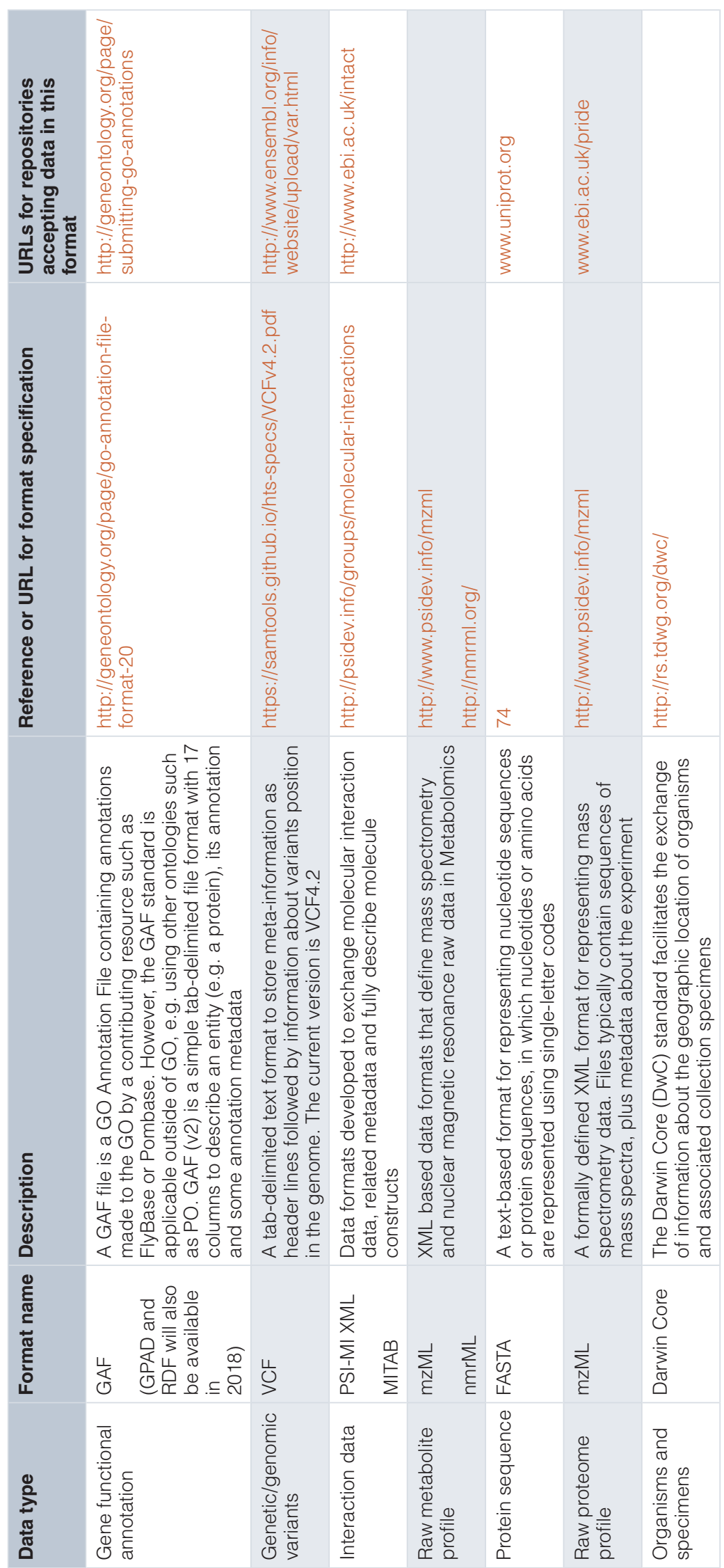




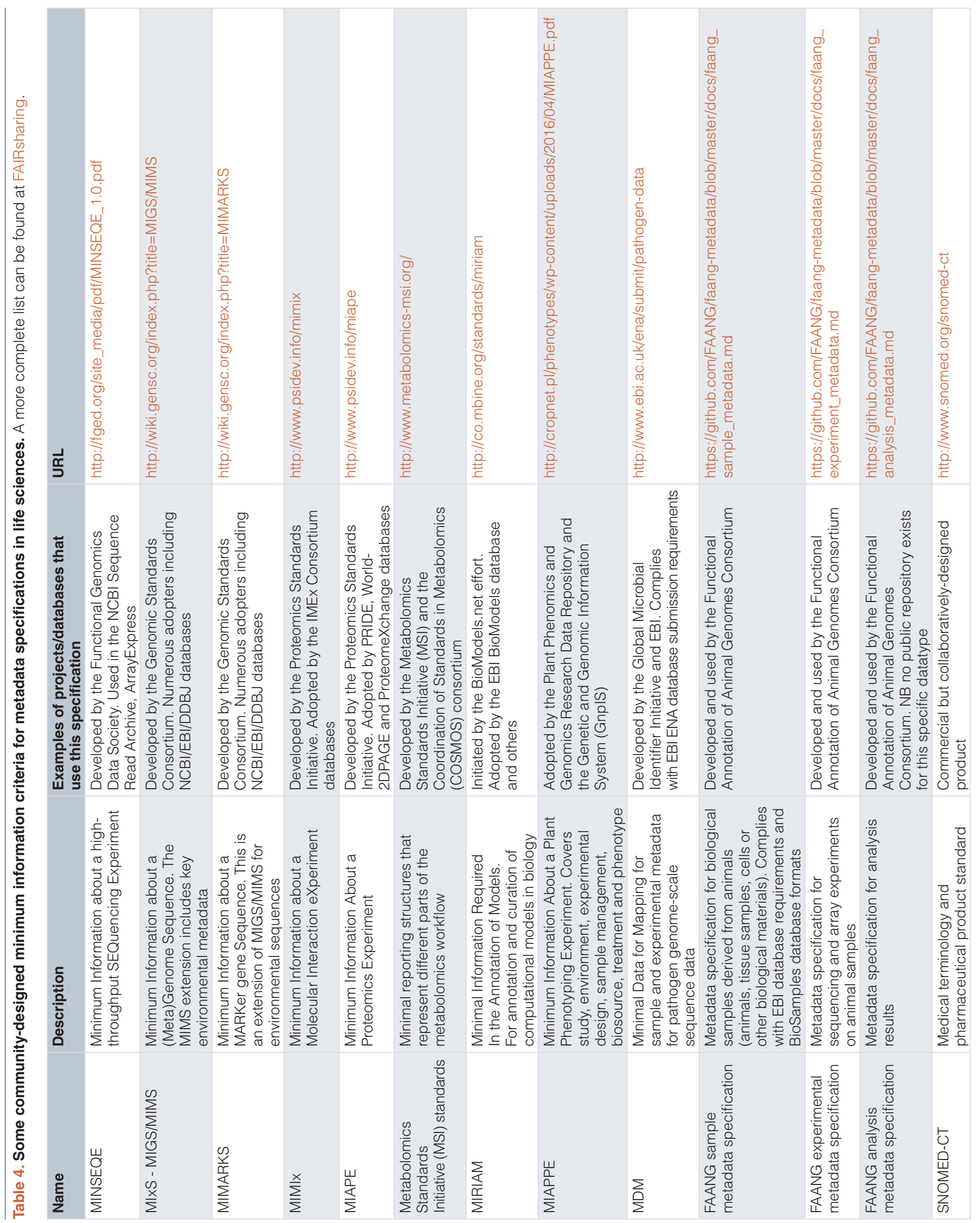




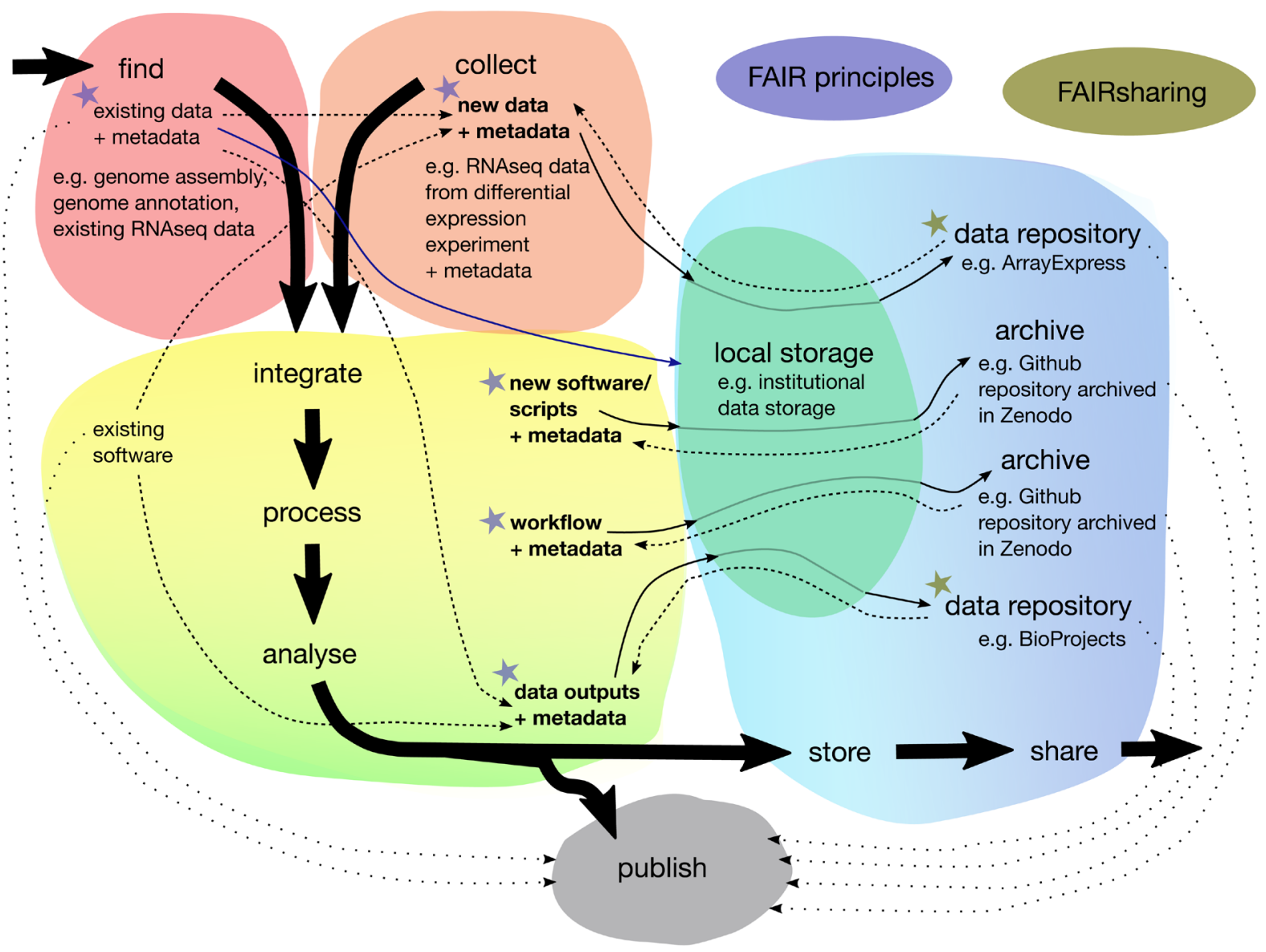

Figure 2. Flowchart of the data life cycle stages applied to an example research project. Bold text indicates new data, software or workflow objects created during the project. Solid thin arrows indicate movement of objects from creation to storage and sharing. Dashed thin arrows indicate where downstream entities should influence decisions made at a given step. (For example, the choice of format, granularity, metadata content and structure of new data collected may be influenced by existing software requirements, existing data characteristics and requirements of the archive where the data will be deposited). Purple stars indicate objects for which the FAIR principles ${ }^{9}$ can provide further guidance. Dotted thin arrows indicate citation of an object using its unique persistent identifier. Brown stars indicate where FAIRsharing can help identify appropriate archives for storing and sharing.

and the level of detail authors provide can vary greatly in practice $^{76,77}$. More recently, many authors have highlighted that full reproducibility requires sharing data and resources at all stages of the scientific process, from raw data (including biological samples) to full methods and analysis workflows ${ }^{1,6,61,77}$. However, this remains a challenge $\mathrm{e}^{78,79}$, as discussed in the Processing and analysing data section. To our knowledge, strategies for enabling computational reproducibility are currently not mandated by any scientific journal.

A recent development in the field of scientific publishing is the establishment of 'data journals': scientific journals that publish papers describing datasets. This gives authors a vehicle to accrue citations (still a dominant metric of academic impact) for data production alone, which can often be labour-intensive and expensive yet is typically not well recognised under the traditional publishing model. Examples of this article type include the Data Descriptor in Scientific Data and the Data Note in GigaScience, which do not include detailed new analysis but rather focus on describing and enabling reuse of datasets.
The movement towards sharing research publications themselves ('Open Access Publishing') has been discussed extensively elsewhere [e.g. 23,80,81]. Publications have associated metadata (creator, date, title etc.; see Dublin Core Metadata Initiative metadata terms) and unique identifiers (PubMed ID for biomedical and some life science journals, DOIs for the vast majority of journals; see Table 5). The ORCID system enables researchers to claim their own unique identifier, which can be linked to their publications. The use of unique identifiers within publications referring to repository records (e.g. genes, proteins, chemical entities) is not generally mandated by journals, although it would ensure a common vocabulary is used and so make scientific results more interoperable and reusable ${ }^{82}$. Some efforts are underway to make this easier for researchers: for example, Genetics and other Genetics Society of America journals assist authors in linking gene names to model organism database entries.

\section{Storing data}

While primary data archives are the best location for raw data and some downstream data outputs (Table 1), researchers also 


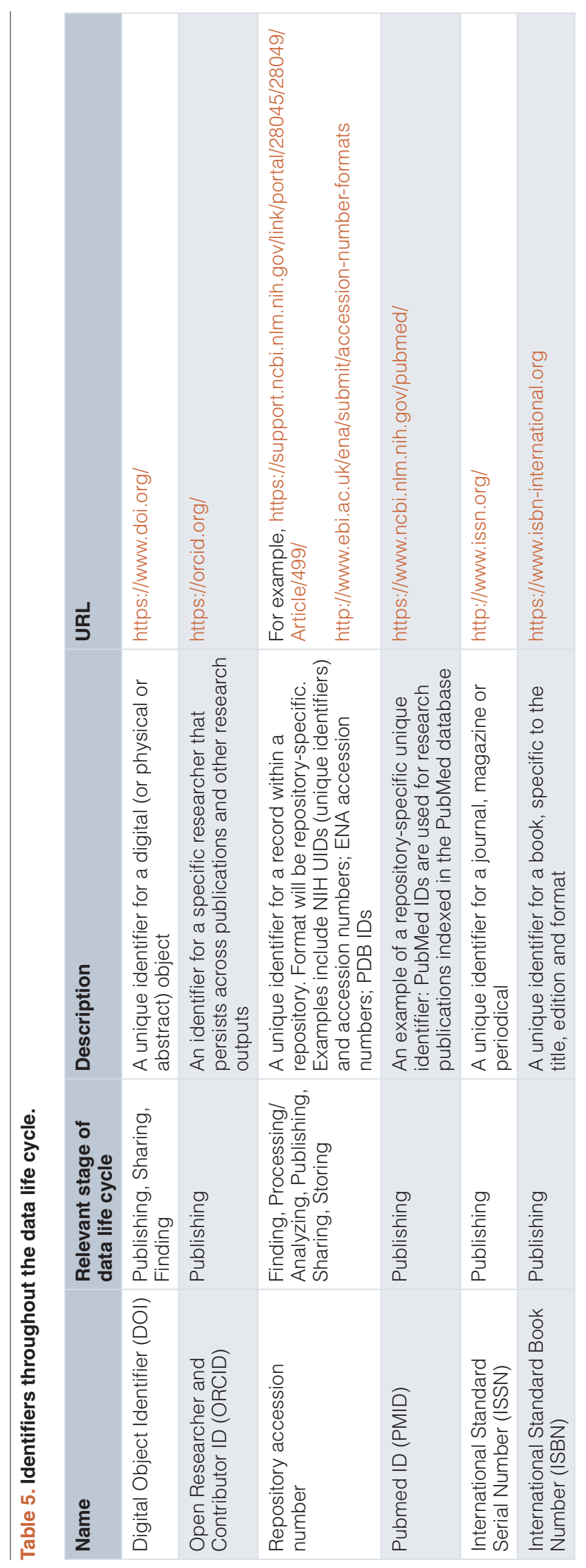


need local data storage solutions during the processing and analysis stages. Data storage requirements vary among research domains, with major challenges often evident for groups working on taxa with large genomes (e.g. crop plants), which require large storage resources, or on human data, where privacy regulations may require local data storage, access controls (e.g. the GA4GH Security Technology Infrastructure document) and conversion to non-identifiable data if data is to be shared (see Sharing data section). For data where privacy is a concern, one approach is separating the data storage from the analysis location and limiting the analysis outputs to 'nondisclosive' results $^{83}$. An example is DataShield ${ }^{83}$, which is mostly used for public health rather than 'omics' data. Subdomain-specific practice should be considered when choosing appropriate formats and linking metadata, as outlined in 84 . In addition, longterm preservation of research data should consider threats such as storage failure, mistaken erasure, bit rot, outdated media, outdated formats, loss of context and organisational failure ${ }^{85}$.

\section{Sharing data}

The best-practice approach to sharing biological data is to deposit it (with associated metadata) in a primary archive suitable for that datatype 8 that complies with FAIR principles. As highlighted in the Storing data section, these archives assure both data storage and public sharing as their core mission, making them the most reliable location for long-term data storage. Alternative data sharing venues (e.g. FigShare, Dryad) do not require or implement specific metadata or data standards. This means that while these venues have a low barrier to entry for submitters, the data is not FAIR unless submitters have independently decided to comply with more stringent criteria. If available, an institutional repository may be a good option if there is no suitable archive for that datatype.

Data with privacy concerns (for example, containing humanderived, commercially-important or sensitive environmental information) can require extensive planning and compliance with a range of institutional and regulatory requirements as well as relevant laws ${ }^{86}$ (for the Australian context, see the Australian National Data Service Publishing and Sharing Sensitive Data Guide, the National Health and Medical Research Council statement on ethical conduct in human research, and the Australian National Medical Research Storage Facility discussion paper on legal, best practice and security frameworks). In particular, it is often necessary for users of the data to be correctly identified, and to subsequently be authenticated via a mechanism such as OpenID, eduGAIN, or (in the Australian context), AAF, which places the onus on ensuring users are correctly identified with institutions that issue their credentials. Knowing who the users are can be used to restrict access, require compliance with the conditions under which the data is provided, and track user activity as an audit trail. The Data Access Compliance Office of the International Cancer Genome Consortium is an example of how to manage requests for access to controlled data. Large-scale collaborations such as the Global Alliance for Genomics and Health $(\mathrm{GA} 4 \mathrm{GH})$ are leading the way in approaches to sharing sensitive data across institutions and jurisdictions (87; also see the GA4GH Privacy and Security Policy). Importantly, plans for data sharing should be made at the start of a research project and reviewed during the project, to ensure ethical approval is in place and that the resources and metadata needed for effective sharing are available at earlier stages of the data life cycle $^{3}$.

In our experience, the majority of life science researchers are familiar with at least some public primary data repositories, and many have submitted data to them previously. A common complaint is around usability of current data submission tools and a lack of transparency around metadata requirements and the rationale for them. Some researchers raise specific issues about the potential limitations of public data repositories where their data departs from the assumptions of the repository (e.g. unusual gene models supported by experimental evidence can be rejected by the automated NCBI curation system). In such cases, researchers can provide feedback to the repositories to deal with such situations, but may not be aware of this - it could be made clearer on the repository websites. Again, this points in part to existing limitations in the undergraduate and postgraduate training received by researchers, where the concepts presented in this article are presented as afterthoughts, if at all. On the repository side, while there is a lot of useful information and training material available to guide researchers through the submission process (e.g. the EMBL-EBI Train Online webinars and online training modules), it is not always linked clearly from the database portals or submission pages themselves. Similarly, while there are specifications and standards available for many kinds of metadata [Table 4; also see FAIRsharing], many do not have example templates available, which would assist researchers in implementing the standards in practice.

\section{What can the research community do to encourage best-practice?}

We believe that the biological/biomedical community and individual researchers have a responsibility to the public to help advance knowledge by making research data FAIR for reuse 9 , especially if the data were generated using public funding. There are several steps that can assist in this mission:

1. Researchers reusing any data should openly acknowledge this fact and fully cite the dataset, using unique identifiers ${ }^{8,10,31}$.

2. Researchers should endeavour to improve their own data management practices in line with best practice in their subdomain - even incremental improvement is better than none!

3. Researchers should provide feedback to their institution, data repositories and bodies responsible for community resources (data standards, controlled vocabularies etc.) where they identify roadblocks to good data management.

4. Senior scientists should lead by example and ensure all the data generated by their laboratories is well-managed, fully annotated with the appropriate metadata and made publicly available in an appropriate repository. 
5. The importance of data management and benefits of data reuse should be taught at the undergraduate and postgraduate levels ${ }^{18}$. Computational biology and bioinformatics courses in particular should include material about data repositories, data and metadata standards, data discovery and access strategies. Material should be domain-specific enough for students to attain learning outcomes directly relevant to their research field.

6. Funding bodies are already taking a lead role in this area by requiring the incorporation of a data management plan into grant applications. A next step would be for a formal check, at the end of the grant period, that this plan has been adhered to and data is available in an appropriate format for reuse ${ }^{10}$.

7. Funding bodies and research institutions should judge quality dataset generation as a valued metric when evaluating grant or promotion applications.

8. Similarly, leadership and participation in community efforts in data and metadata standards, and open software and workflow development should be recognised as academic outputs.

9. Data repositories should ensure that the data deposition and third-party annotation processes are as FAIR and painless as possible to the naive researcher, without the need for extensive bioinformatics support $^{40}$.

10. Journals should require editors and reviewers to check manuscripts to ensure that all data, including research software code and samples where appropriate, have been made publicly available in an appropriate repository, and that methods have been described in enough detail to allow re-use and meaningful reanalysis ${ }^{8}$.

\section{Conclusions}

While the concept of a life cycle for research data is appealing from an Open Science perspective, challenges remain for life science researchers to put this into practice. Among attendees of the workshop series that gave rise to this publication, we noted limited awareness among attendees of the resources available to researchers that assist in finding, collecting, processing, analysis, publishing, storing and sharing FAIR data. We believe this article provides a useful overview of the relevant concepts and an introduction to key organisations, resources and guidelines to help researchers improve their data management practices.

Furthermore, we note that data management in the era of biology as a data science is a complex and evolving topic and both best practices and challenges are highly domain-specific, even within the life sciences. This factor may not always be appreciated at the organisational level, but has major practical implications for the quality and interoperability of shared life science data. Finally, domain-specific education and training in data management would be of great value to the life science research workforce, and we note an existing gap at the undergraduate, postgraduate and short course level in this area.

\section{Competing interests}

No competing interests were disclosed.

\section{Grant information}

This publication was possible thanks to funding support from the University of Melbourne and Bioplatforms Australia (BPA) via an Australian Government NCRIS investment (to EMBL-ABR).

The funders had no role in study design, data collection and analysis, decision to publish, or preparation of the manuscript.

\section{Acknowledgements}

The authors thank Dan Bolser for his involvement in the EMBL-ABR Data Life Cycle workshops, and all workshop participants for sharing their experiences and useful discussions.
1. Cohen-Boulakia S, Belhajjame K, Collin O, et al:: Scientific workflows for computational reproducibility in the life sciences: status, challenges and opportunities. Future Gener Comput Syst. 2017; 75: 284-298. Publisher Full Text

2. Hampton SE, Anderson SS, Bagby SC, et al:: The Tao of open science for ecology. Ecosphere. 2015; 6(7): 1-13. Publisher Full Text

3. Lord P, Macdonald A, Sinnot R, et al:: Large-scale data sharing in the life sciences: Data standards, incentives, barriers and funding models. UK e-Science; 2005; Report No.: UKeS-2006-02. Reference Source

4. Piwowar HA, Vision $\mathrm{TJ}$ : Data reuse and the open data citation advantage. Peer 2013; 1: e175.

PubMed Abstract | Publisher Full Text | Free Full Text

5. Vines TH, Albert AY, Andrew RL, et al.: The availability of research data declines rapidly with article age. Curr Biol. 2014; 24(1): 94-97. PubMed Abstract | Publisher Full Text

6. Lewis J, Breeze CE, Charlesworth J, et al.: Where next for the reproducibility agenda in computational biology? BMC Syst Biol. 2016; 10(1): 52 PubMed Abstract | Publisher Full Text | Free Full Text

7. Voytek B: The Virtuous Cycle of a Data Ecosystem. PLoS Comput Biol. 2016; 12(8): e1005037.

PubMed Abstract | Publisher Full Text | Free Full Text

8. Whitlock MC: Data archiving in ecology and evolution: best practices. Trends Ecol Evol. 2011; 26(2): 61-65. PubMed Abstract | Publisher Full Text

9. Wilkinson MD, Dumontier M, Aalbersberg IJ, et al:: The FAIR Guiding Principles for scientific data management and stewardship. Sci Data. 2016; 3: 160018. PubMed Abstract | Publisher Full Text | Free Full Text

10. Van Tuyl S, Whitmire AL: Water, Water, Everywhere: Defining and Assessing 
Data Sharing in Academia. PLoS One. 2016; 11(2): e0147942. PubMed Abstract | Publisher Full Text | Free Full Text

11. Rüegg J, Gries C, Bond-Lamberty B, et al.: Completing the data life cycle: using information management in macrosystems ecology research. Front Ecol Environ. Ecological Society of America. 2014; 12(1): 24-30. Publisher Full Text

12. Moody D, Walsh $\mathrm{P}$ : Measuring the value of information: an asset valuation approach. European Conference on Information Systems. 1999; 17. Reference Source

13. Mons B, Neylon C, Velterop J, et al:: Cloudy, increasingly FAIR; revisiting the FAIR Data guiding principles for the European Open Science Cloud. Inf Serv Use. IOS Press; 2017; 37(1): 49-56. Publisher Full Text

14. Michener WK, Jones MB: Ecoinformatics: supporting ecology as a dataintensive science. Trends Ecol Evol. 2012; 27(2): 85-93. PubMed Abstract | Publisher Full Text

15. Lenhardt WC, Ahalt S, Blanton B, et al:: Data management lifecycle and software lifecycle management in the context of conducting science. J Open Res Softw. 2014; 2(1): e15.

Publisher Full Text

16. Data's shameful neglect. Nature. 2009; 461(7261): 145 PubMed Abstract | Publisher Full Text

17. Strasser CA, Hampton SE: The fractured lab notebook: undergraduates and ecological data management training in the United States. Ecosphere. Ecological Society of America. 2012; 3(12): 1-18. Publisher Full Text

18. Tenopir C, Allard S, Sinha P, et al:: Data Management Education from the Perspective of Science Educators. International Journal of Digital Curation. 2016; 11(1): 232-251. Publisher Full Text

19. Alidina HM, Fisher D, Stienback $C$, et al.: Assessing and managing data. In Ardron J, Possingham H, Klein C, editors. Marxan Good Practices Handbook Vancouver, Canada; 2008; 14-20. Reference Source

20. Simms S, Strong $\mathrm{M}$, Jones $\mathrm{S}$, et al:: The future of data management planning: tools, policies, and players. International Journal of Digital Curation. 2016; 11(1): 208-217. Publisher Full Tex

21. Schneider MV, Griffin PC, Tyagi S, et al:: Establishing a distributed national research infrastructure providing bioinformatics support to life science researchers in Australia. Brief Bioinform. 2017.

Publisher Full Text

22. Womack RP: Research Data in Core Journals in Biology, Chemistry, Mathematics, and Physics. PLoS One. 2015; 10(12): e0143460. PubMed Abstract | Publisher Full Text | Free Full Text

23. McKiernan EC, Bourne PE, Brown CT, et al.: How open science helps researchers succeed. eLife. 2016; 5: pii: e16800. PubMed Abstract | Publisher Full Text | Free Full Text

24. Sansone SA, Rocca-Serra P, Field D, et al:: Toward interoperable bioscience data. Nat Genet. 2012; 44(2): 121-126. PubMed Abstract | Publisher Full Text | Free Full Text

25. Cook CE, Bergman MT, Finn RD, et al: The European Bioinformatics Institute in 2016: Data growth and integration. Nucleic Acids Res. 2016; 44(D1): D20-6. PubMed Abstract | Publisher Full Text | Free Full Text

26. NCBI Resource Coordinators: Database Resources of the National Center for Biotechnology Information. Nucleic Acids Res. 2017; 45(D1): D12-D17. PubMed Abstract | Publisher Full Text | Free Full Text

27. Mashima J, Kodama Y, Fujisawa T, et al.: DNA Data Bank of Japan. Nucleic Acids Res. 2017; 45(D1): D25-D31.

PubMed Abstract | Publisher Full Text | Free Full Text

28. SIB Swiss Institute of Bioinformatics Members: The SIB Swiss Institute of Bioinformatics' resources: focus on curated databases. Nucleic Acids Res. 2016; 44(D1): D27-37.

PubMed Abstract | Publisher Full Text | Free Full Text

29. Burley SK, Berman HM, Kleywegt GJ, et al:: Protein Data Bank (PDB): The Single Global Macromolecular Structure Archive. Methods Mol Biol. 2017; 1607: 627-641. PubMed Abstract | Publisher Full Text | Free Full Text

30. Beagrie N, Houghton J: The value and impact of the European Bioinformatics Institute: executive summary. Charles Beagrie Ltd.; 2016. Reference Source

31. Thessen AE, Patterson DJ: Data issues in the life sciences. Zookeys. 2011; (150): $15-51$.

PubMed Abstract | Publisher Full Text | Free Full Text

32. Brookes AJ, Robinson PN: Human genotype-phenotype databases: aims, challenges and opportunities. Nat Rev Genet. 2015; 16(12): 702-715. PubMed Abstract | Publisher Full Text

33. Joly $Y$, Dove ES, Knoppers BM, et al.: Data sharing in the post-genomic world: the experience of the International Cancer Genome Consortium (ICGC) Data Access Compliance Office (DACO). PLoS Comput Biol. 2012; 8(7): e1002549. PubMed Abstract | Publisher Full Text | Free Full Text

34. Wong KM, Langlais K, Tobias GS, et al:: The dbGaP data browser: a new tool for browsing dbGaP controlled-access genomic data. Nucleic Acids Res. 2017 45(D1): D819-D826.

PubMed Abstract | Publisher Full Text | Free Full Tex

35. Global Alliance for Genomics and Health: GENOMICS. A federated ecosystem for sharing genomic, clinical data. Science. 2016; 352(6291): 1278-80.

PubMed Abstract | Publisher Full Text

36. Costello MJ, Appeltans W, Bailly N, et al:: Strategies for the sustainability of online open-access biodiversity databases. Biol Conserv. 2014; 173: 155-165. Publisher Full Text

37. Oliver SG, Lock A, Harris MA, et al.: Model organism databases: essential resources that need the support of both funders and users. BMC Biol. 2016; 14: 49. PubMed Abstract | Publisher Full Text | Free Full Text

38. Kaiser J: BIOMEDICAL RESOURCES. Funding for key data resources in jeopardy. Science. 2016; 351(6268): 14

PubMed Abstract | Publisher Full Text

39. Schnoes AM, Brown SD, Dodevski I, et al.: Annotation error in public databases: misannotation of molecular function in enzyme superfamilies. PLoS Comput Biol. 2009; 5(12): e1000605.

PubMed Abstract | Publisher Full Text | Free Full Text

40. Bengtsson-Palme J, Boulund F, Edström R, et al.: Strategies to improve usability and preserve accuracy in biological sequence databases. Proteomics. 2016 16(18): 2454-2460.

PubMed Abstract | Publisher Full Text

41. ten Hoopen $\mathrm{P}$, Amid $\mathrm{C}$, Buttigieg PL, et al:: Value, but high costs in postdeposition data curation. Database (Oxford). 2016; 2016: pii: bav126. PubMed Abstract | Publisher Full Text | Free Full Text

42. McQuilton $\mathrm{P}$, Gonzalez-Beltran A, Rocca-Serra $\mathrm{P}$, et al:: BioSharing: curated and crowd-sourced metadata standards, databases and data policies in the life sciences. Database (Oxford). 2016; 2016: pii: baw075 PubMed Abstract | Publisher Full Text | Free Full Text

43. Malone J, Stevens R, Jupp S, et al.: Ten Simple Rules for Selecting a Bioontology. PLoS Comput Biol. 2016; 12(2): e1004743.

PubMed Abstract | Publisher Full Text | Free Full Text

44. Rocca-Serra P, Salek RM, Arita M, et al:: Data standards can boost metabolomics research, and if there is a will, there is a way. Metabolomics. 2016; $12: 14$.

PubMed Abstract | Publisher Full Text | Free Full Text

45. Tenenbaum JD, Sansone SA, Haendel M: A sea of standards for omics data: sink or swim? J Am Med Inform Assoc. 2014; 21(2): 200-203.

PubMed Abstract | Publisher Full Text | Free Full Text

46. Taylor CF, Field D, Sansone SA, et al.: Promoting coherent minimum reporting guidelines for biological and biomedical investigations: the MIBBI project. Nat Biotechnol. 2008; 26(8): 889-896.

PubMed Abstract | Publisher Full Text | Free Full Text

47. Gomez-Cabrero D, Abugessaisa I, Maier D, et al:: Data integration in the era of omics: current and future challenges. BMC Syst Biol. 2014; 8 Suppl 2: I1. PubMed Abstract | Publisher Full Text | Free Full Text

48. Goble $C$, Stevens R: State of the nation in data integration for bioinformatics. J Biomed Inform. 2008; 41(5): 687-693.

PubMed Abstract | Publisher Full Text

49. Mungall CJ, McMurry JA, Köhler S, et al:: The Monarch Initiative: an integrative data and analytic platform connecting phenotypes to genotypes across species. Nucleic Acids Res. 2017; 45(D1): D712-D722. PubMed Abstract | Publisher Full Text | Free Full Text

50. Barone L, Williams J, Micklos D: Unmet needs for analyzing biological big data: A survey of 704 NSF principal investigators. PLoS Comput Biol. 2017; 13(10): e1005755.

PubMed Abstract | Publisher Full Text | Free Full Text

51. Hinsen K: ActivePapers: a platform for publishing and archiving computeraided research [version 3; referees: 3 approved]. F1000Res. 2015; 3: 289. PubMed Abstract | Publisher Full Text | Free Full Text

52. Piccolo SR, Frampton MB: Tools and techniques for computational reproducibility. Gigascience. 2016; 5(1): 30 .

PubMed Abstract | Publisher Full Text | Free Full Text

53. Jiménez RC, Kuzak M, Alhamdoosh M, et al.: Four simple recommendations to encourage best practices in research software [version 1; referees: 3 approved]. F1000Res. 2017; 6: pii: ELIXIR-876. PubMed Abstract | Publisher Full Text | Free Full Text

54. Artaza $\mathrm{H}$, Chue Hong N, Corpas $\mathrm{M}$, et al:: Top 10 metrics for life science software good practices [version 1; referees: 2 approved]. F1000Res. 2016; 5: pii: ELIXIR-2000. PubMed Abstract | Publisher Full Text | Free Full Text

55. Wilson G, Bryan J, Cranston $\mathrm{K}$, et al:: Good enough practices in scientific computing. PLOS Comput Biol. 2017; 13(6): e1005510. PubMed Abstract | Publisher Full Text | Free Full Text

56. Kazic T: Ten Simple Rules for Experiments' Provenance. PLoS Comput Biol. 2015; 11(10): e1004384.

PubMed Abstract | Publisher Full Text | Free Full Text

57. Faulconbridge $\mathrm{A}$, Burdett $\mathrm{T}$, Brandizi $\mathrm{M}$, et al:: Updates to BioSamples database at European Bioinformatics Institute. Nucleic Acids Res. 2014; 42(Database issue): D50-2.

PubMed Abstract | Publisher Full Text | Free Full Text 
58. Schilthuizen M, Vairappan CS, Slade EM, et al:: Specimens as primary data: museums and 'open science'. Trends Ecol Evol. 2015; 30(5): 237-238. PubMed Abstract | Publisher Full Text

59. Turney S, Cameron ER, Cloutier CA, et al:: Non-repeatable science: assessing the frequency of voucher specimen deposition reveals that most arthropod research cannot be verified. PeerJ. 2015; 3: e1168. PubMed Abstract | Publisher Full Text | Free Full Text

60. Walters C, Volk GM, Richards CM: Genebanks in the post-genomic age: emerging roles and anticipated uses. Biodiversity. Taylor \& Francis; 2008; 9(1-2): 68-71.

Publisher Full Text

61. Lloyd K, Franklin C, Lutz C, et al:: Reproducibility: use mouse biobanks or lose them. Nature. 2015; 522(7555): 151-153. PubMed Abstract | Publisher Full Text | Free Full Text

62. Watson PH: Biospecimen Complexity-the Next Challenge for Cancer Research Biobanks? Clin Cancer Res. 2017; 23(4): 894-898. PubMed Abstract | Publisher Full Text

63. Schnell S: Ten Simple Rules for a Computational Biologist's Laboratory Notebook. PLoS Comput Biol. 2015; 11(9): e1004385. PubMed Abstract | Publisher Full Text | Free Full Text

64. Walsh E, Cho I: Using Evernote as an electronic lab notebook in a translational science laboratory. J Lab Autom. 2013; 18(3): 229-234. PubMed Abstract | Publisher Full Text

65. Smith VS, Rycroft SD, Brake I, et al:: Scratchpads 2.0: a Virtual Research Environment supporting scholarly collaboration, communication and data publication in biodiversity science. Zookeys. 2011; (150): 53-70. PubMed Abstract | Publisher Full Text | Free Full Text

66. Boettiger C: A reproducible R notebook using Docker. In: Kitzes J, Turek D, Deniz F, editors. The practice of reproducible research: case studies and lessons from the data-intensive sciences. Oakland, CA: University of California Press; 2017. Reference Source

67. Koshland DE Jr: The price of progress. Science. 1988; 241(4866): 637. PubMed Abstract | Publisher Full Text

68. Jasny BR: Realities of data sharing using the genome wars as case study - an historical perspective and commentary. EPJ Data Sci. 2013; 2: 1. Publisher Full Text

69. Caetano DS, Aisenberg A: Forgotten treasures: the fate of data in animal behaviour studies. Anim Behav. 2014; 98: 1-5. Publisher Full Text

70. Piwowar HA, Chapman WW: A review of journal policies for sharing research data. Open scholarship: authority, community, and sustainability in the age of Web 20 Proceedings of the 12th International Conference on Electronic Publishing (ELPUB) 2008. Toronto, Canada; 2008. Reference Source

71. National Research Council, Division on Earth and Life Studies, Board on Life Sciences, et al.: Sharing Publication-Related Data and Materials: Responsibilities of Authorship in the Life Sciences. National Academies Press: 2003.

PubMed Abstract | Publisher Full Text

72. Kilkenny C, Browne WJ, Cuthill IC, et al: Improving bioscience research reporting: the ARRIVE guidelines for reporting animal research. PLOS Biol.
2010; 8(6): e1000412.

PubMed Abstract | Publisher Full Text | Free Full Text

73. Naughton L, Kernohan D: Making sense of journal research data policies. Insights. UKSG in association with Ubiquity Press; 2016; 29(1): 84-89. Publisher Full Text

74. Pearson WR, Lipman DJ: Improved tools for biological sequence comparison. Proc Natl Acad Sci U S A. 1988; 85(8): 2444-2448. PubMed Abstract | Publisher Full Text | Free Full Text

75. Cock PJ, Fields CJ, Goto N, et al.: The Sanger FASTQ file format for sequences with quality scores, and the Solexa/lllumina FASTQ variants. Nucleic Acids Res. 2010; 38(6): 1767-1771.

PubMed Abstract | Publisher Full Text | Free Full Text

76. Iqbal SA, Wallach JD, Khoury MJ, et al.: Reproducible Research Practices and Transparency across the Biomedical Literature. PLOS Biol. 2016; 14(1): e1002333.

PubMed Abstract | Publisher Full Text | Free Full Text

77. Nekrutenko A, Taylor J: Next-generation sequencing data interpretation: enhancing reproducibility and accessibility. Nat Rev Genet. 2012; 13(9): 667-672.

PubMed Abstract | Publisher Full Text

78. Ioannidis JP, Khoury MJ: Improving validation practices in "omics" research Science. 2011; 334(6060): 1230-1232.

PubMed Abstract | Publisher Full Text | Free Full Text

79. Errington TM, lorns E, Gunn W, et al:: An open investigation of the reproducibility of cancer biology research. eLife. 2014; 3: e04333. PubMed Abstract | Publisher Full Text | Free Full Text

80. Wolpert AJ: For the sake of inquiry and knowledge--the inevitability of open access. N Engl J Med. Mass Medical Soc; 2013; 368(9): 785-787. PubMed Abstract | Publisher Full Text

81. Laakso M, Welling $\mathrm{P}$, Bukvova $\mathrm{H}$, et al.: The development of open access journal publishing from 1993 to 2009. PLoS One. 2011; 6(6): e20961. PubMed Abstract | Publisher Full Text | Free Full Text

82. McMurry JA, Juty N, Blomberg N, et al.: Identifiers for the 21st century: How to design, provision, and reuse persistent identifiers to maximize utility and impact of life science data. PLOS Biol. 2017; 15(6): e2001414. PubMed Abstract | Publisher Full Text | Free Full Text

83. Wilson RC, Butters OW, Avraam D, et al.: DataSHIELD - new directions and dimensions. Data Science Journal. 2017; 16: 21. Publisher Full Text

84. Hart EM, Barmby P, LeBauer D, et al:: Ten Simple Rules for Digital Data Storage. PLoS Comput Biol. 2016; 12(10): e1005097. PubMed Abstract | Publisher Full Text | Free Full Text

85. Baker M, Keeton K, Martin S: Why traditional storage systems don't help us save stuff forever. Proc 1st IEEE Workshop on Hot Topics in System Dependability. 2005; 2005-2120. Reference Source

86. Kahn SD: On the future of genomic data. Science. 2011; 331(6018): 728-729. PubMed Abstract | Publisher Full Text

87. Siu LL, Lawler M, Haussler D, et al.: Facilitating a culture of responsible and effective sharing of cancer genome data. Nat Med. 2016; 22(5): 464-471. PubMed Abstract | Publisher Full Text | Free Full Text 


\section{Open Peer Review}

\section{Current Peer Review Status:}

\section{Version 2}

Reviewer Report 30 July 2018

https://doi.org/10.5256/f1000research.16485.r34683

(C) 2018 Nahnsen S. This is an open access peer review report distributed under the terms of the Creative Commons Attribution License, which permits unrestricted use, distribution, and reproduction in any medium, provided the original work is properly cited.

\section{Sven Nahnsen}

Quantitative Biology Center (QBiC), University of Tübingen, Tübingen, Germany

The authors have sufficiently addressed the issues that were raised. I am happy to recommend the article by Griffin et al. for indexing.

Competing Interests: No competing interests were disclosed.

Reviewer Expertise: Data management, multi-omics bioinformatics

I confirm that I have read this submission and believe that I have an appropriate level of expertise to confirm that it is of an acceptable scientific standard.

Reviewer Report 19 June 2018

https://doi.org/10.5256/f1000research.16485.r34682

(C) 2018 Starlinger J. This is an open access peer review report distributed under the terms of the Creative Commons Attribution License, which permits unrestricted use, distribution, and reproduction in any medium, provided the original work is properly cited.

\section{Johannes Starlinger}

1 Department of Anesthesiology and Operative Intensive Care Medicine, Charité Universitätsmedizin Berlin, Berlin, Germany

2 Department of Computer Science, Humboldt-Universität zu Berlin, Berlin, Germany

The authors have more than adequately addressed all issues raised in the review, both in their answers to the reviewer's comments and in the amendments of the paper. Thank you very much for this very instructive introductory read for data management for life sciences researchers! 
Competing Interests: No competing interests were disclosed.

Reviewer Expertise: Biomedical knowledge management, systems architectures, clinical informatics

I confirm that I have read this submission and believe that I have an appropriate level of expertise to confirm that it is of an acceptable scientific standard.

\section{Version 1}

Reviewer Report 15 December 2017

https://doi.org/10.5256/f1000research.13366.r27113

(C) 2017 Nahnsen S. This is an open access peer review report distributed under the terms of the Creative Commons Attribution License, which permits unrestricted use, distribution, and reproduction in any medium, provided the original work is properly cited.

\section{Sven Nahnsen \\ ${ }^{1}$ Quantitative Biology Center (QBiC), University of Tübingen, Tübingen, Germany \\ 2 Quantitative Biology Center (QBiC), University of Tübingen, Tübingen, Germany}

The article "Best practice data life cycle approaches for the life sciences", submitted by Griffin et al. reports opinions on how to best manage the growing complexity of scientific data in the life sciences.

The article touches on an extremely important topic that is currently very purely covered in the literature. In fact, data-driven approaches in the biosciences will strongly rely on professional concepts of data management. In brief, I recommend the indexing of the article, as we urgently need stronger awareness of this topic, upon the implementation of some (probably rather minor) changes to the article. The article nicely illustrates the needs in data life cycle management and also suggests best concepts to be followed by researchers. The main content of the article has been compiled based on a workshop that was attended by the authors. At some statements the article reads like the minutes of this meeting; I suggest editing the corresponding paragraphs to avoid the impression of reading meeting minutes.

I suggest the following issues to be fixed before indexing:

Figure 1: This illustration is very important and can be used by many readers. I suggest to use figures wherever possible to replace the words such as "finding", "integrating", ...

The reference to Figure 1 in the second paragraph states that it illustrates a specific aim to the life sciences. I don't see which of these points should be specific to the life science, but would rather argue that these principles are rather generic and provides a cycle for business intelligence processes in general. It might also be a good location to reference the DAMA (Data management association internation, dama.org) and specifically to the DAMA 
Body of Knowledge, which is one of the few references for data management and also data life cycle considerations. Further needed references should hint to the Global Alliance for Genomics and Health (ga4gh.org).

Page 13: The paragraph on data sharing missing some discussion on authentication issues. I would like see some introduction and discussion to the OpenID concept. Especially for medical data there need to be appropriate mechanisms to trace users, concepts for data privacy and so on. As a best practice use case for these topics, the mechanism from ICGC could be introduced.

The following paragraph states: "A few workshop participants...". Rephrase, no meeting minutes..

I would have loved to see more use cases/examples for the individual best practices. E.g. for the data sharing the ICGC efforts could be described more thoroughly.

The article would benefit for 2-3 additional figures. I guess it could be a nice figure to illustrate the concept of controlled vocabularies and/or ontologies. While this seems to be trivial for bioinformaticians/computer scientists, it is not that obvious what it means to noncomputer scientists; inspiration for figures can also be obtained by the data sharing mechanisms for the Global alliance for Genomics and Health

Minor things:

The forth paragraph in the introduction starts with "During the week of 24-28 October 2016...". I suggest either avoiding that paragraph or formulating it differently. The reader should not be reading the meeting minutes.

Is the topic of the opinion article discussed accurately in the context of the current literature?

Yes

Are all factual statements correct and adequately supported by citations? Yes

Are arguments sufficiently supported by evidence from the published literature? Yes

Are the conclusions drawn balanced and justified on the basis of the presented arguments? Partly

Competing Interests: No competing interests were disclosed.

Reviewer Expertise: Data management, multi-omics bioinformatics

I confirm that I have read this submission and believe that I have an appropriate level of expertise to confirm that it is of an acceptable scientific standard, however I have significant reservations, as outlined above. 
Reader Comment 27 May 2018

\section{Pip Griffin}

\section{Response to Review 1}

Thank you very much to Dr. Nahnsen for his review. We have responded to his comments below (reviewer comments in italics, our responses in plain text).

The article "Best practice data life cycle approaches for the life sciences", submitted by Griffin et al. reports opinions on how to best manage the growing complexity of scientific data in the life sciences.

The article touches on an extremely important topic that is currently very purely covered in the literature. In fact, data-driven approaches in the biosciences will strongly rely on professional concepts of data management. In brief, I recommend the indexing of the article, as we urgently need stronger awareness of this topic, upon the implementation of some (probably rather minor) changes to the article. The article nicely illustrates the needs in data life cycle management and also suggests best concepts to be followed by researchers.

Thank you.

The main content of the article has been compiled based on a workshop that was attended by the authors. At some statements the article reads like the minutes of this meeting; I suggest editing the corresponding paragraphs to avoid the impression of reading meeting minutes.

We have edited the Introduction (para 4), Integrating, Processing and Analysing Data section (para 4), the Sharing Data section (para 2) and the Conclusions section (para 1) to remove details of the events of the workshop, while still mentioning briefly in the

Introduction (para 4) that this article arose from the material we presented and discussed in this workshop series.

I suggest the following issues to be fixed before indexing:

Figure 1: This illustration is very important and can be used by many readers. I suggest to use figures wherever possible to replace the words such as "finding", "integrating", ... We experimented with adding icons to represent the life cycle stages, but found it too difficult to choose a single icon to summarise each complex stage. (For example: the 'Storing Data' stage text covers local data storage, primary archives, privacy and security considerations; one icon would necessarily omit or de-emphasise some of these.) Our attempts gave a misleading aura of simplicity, which we wanted to avoid, and so we prefer to retain the words in the figure, which map readily to the text of the article which contains the detail.

The reference to Figure 1 in the second paragraph states that it illustrates a specific aim to the life sciences. I don't see which of these points should be specific to the life science, but would rather argue that these principles are rather generic and provides a cycle for business intelligence processes in general. It might also be a good location to reference the DAMA (Data management association internation, dama.org) and specifically to the DAMA 
Body of Knowledge, which is one of the few references for data management and also data life cycle considerations. Further needed references should hint to the Global Alliance for Genomics and Health (ga4gh.org).

We agree that data life cycle principles can cut across disciplines and have mentioned other examples of published data lifecycle figures in the Introduction, para 2. As described in more detail in our response to Dr. Starlinger's review, we believe that our data lifecycle model is better suited to the way life science researchers work than more generic models. Specifically, we have included distinct steps for finding existing data and collecting new data (different from e.g. the USGS data lifecycle model) because in life science research these two steps typically have different limitations and considerations. We have included distinct 'publish' and 'share' steps (unlike the USGS, DataOne and Digital Curation Centre models) since publishing manuscripts and sharing data are highly distinct in the minds of most life science researchers due to the publication focus of life science research. Some models (e.g. the DataOne and Digital Curation Centre models) break down the 'collecting data' step (e.g. into collecting, quality-assuring and describing data) but we believe these stages are already rather well understood to be part of the data collection process in the life sciences and have kept them together.

We have been unable to find GA4GH publications dealing with the research data lifecycle but have now cited GA4GH documents in the Storing Data (para 1) and Sharing Data (para 1) sections. We have been unable to source a copy of DAMA International's Guide to the Data Management Body of Knowledge (https://technicspub.com/dmbok/) and so have not included this reference.

Page 13: The paragraph on data sharing missing some discussion on authentication issues. I would like see some introduction and discussion to the OpenID concept. Especially for medical data there need to be appropriate mechanisms to trace users, concepts for data privacy and so on. As a best practice use case for these topics, the mechanism from ICGC could be introduced.

In the interests of keeping the paper a concise introduction to the concepts, we decided not to delve into too much detail around data privacy considerations, a topic that indeed warrants entire papers to itself. However we have now expanded the text in the Finding Data section (para 3), the Storing Data section (para 1) and the Sharing Data section (para 1) to make it clear to readers that for medical data, much extra planning and effort is required to deal with these considerations. We have also provided some explanation of why authentication might be necessary, links to some of the relevant technologies, and a reference (as suggested) to the practices of the ICGC.

The following paragraph states: "A few workshop participants...". Rephrase, no meeting minutes..

Done (Sharing Data section, para 2).

I would have loved to see more use cases/examples for the individual best practices. E.g. for the data sharing the ICGC efforts could be described more thoroughly. 
As the paper is aimed at individual researchers, we wanted to avoid an excessive focus on large-scale research consortium efforts, as the resources such projects have available for data management are likely to be far beyond what individual researchers can access. However, we acknowledge these efforts often set a 'best-practice' standard and so we have now mentioned the Monarch Initiative (Integrating, Processing and Analysing Data section, para 1), the GA4GH (Sharing Data section, para 1) and the ICGC (cited in Finding Data section, para 2).

The article would benefit for 2-3 additional figures. I guess it could be a nice figure to illustrate the concept of controlled vocabularies and/or ontologies. While this seems to be trivial for bioinformaticians/computer scientists, it is not that obvious what it means to non-computer scientists; inspiration for figures can also be obtained by the data sharing mechanisms for the Global alliance for Genomics and Health

We have now included a second figure, an example flowchart (Figure 2) showing how the data life cycle might be used in practice and how downstream considerations influence choices made at each step. An extra figure illustrating CVs/ontologies we judged would make the paper somewhat unbalanced - we have referenced other articles (Thessen and Paterson 2001, Malone et al. 2016) that are good starting points for researchers keen to learn about this topic.

The forth paragraph in the introduction starts with "During the week of 24-28 October 2016...". I suggest either avoiding that paragraph or formulating it differently. The reader should not be reading the meeting minutes.

We have retained some reference to the origin of this article but rewritten the paragraph ( Introduction, para 4) to avoid an appearance of meeting minutes.

Competing Interests: No competing interests were disclosed.

Reviewer Report 21 November 2017

https://doi.org/10.5256/f1000research.13366.r27111

(C) 2017 Starlinger J. This is an open access peer review report distributed under the terms of the Creative Commons Attribution License, which permits unrestricted use, distribution, and reproduction in any medium, provided the original work is properly cited.

\footnotetext{
Johannes Starlinger

1 Department of Anesthesiology and Operative Intensive Care Medicine, Charité Universitätsmedizin Berlin, Berlin, Germany

2 Department of Computer Science, Humboldt-Universität zu Berlin, Berlin, Germany

3 Department of Anesthesiology and Operative Intensive Care Medicine, Charité -
} 
Universitätsmedizin Berlin, Berlin, Germany

${ }^{4}$ Department of Computer Science, Humboldt-Universität zu Berlin, Berlin, Germany

The article gives a brief overview of the data life cycle in the life sciences and offers an entry point for accessing relevant information about current approaches to increasing compliance with the FAIR data sharing principles at each step of this life cycle. It expressly targets "life science researchers wanting to improve their data management practice" and is labeled as an Opinion article.

The article is well written and comfortable to read, and the concise presentation follows a clear structure. While to me as a biomedical data researcher, who may not strictly belong to the target audience, the article provided only little additional insight, I can well see how - as an entry point the article provides valuable information to its target audience.

That said, I believe the article needs clarification and some extension in a few places:

The list of authors is quite extensive. Please clarify the roles of the authors in conception/conduction/preparation of the manuscript.

How exactly does the proposed data life cycle differ from related (cited) suggestions, and why? How is it 'aimed at life science researchers specifically'? (Introduction)

The tabular overviews of existing resources are a nice asset but they are, of course, not exhaustive. Please clarify how the selections of databases/registries, tools, ontologies etc were made for inclusion in the article - and possibly state where to find more complete lists of resources for the life sciences.

The integrating step of the life cycle has no description in the article - even though this is a very intricate step that often has great influence when collecting data (e.g., the choice of ontologies to use for describing collected data and metadata will often depend on the ontologies used in re-used (found) data), and, even more, is at the core of making datasets interoperable, i.e., making them integratable with newly collected data.

In the processing step, you make no mention of Scientific Workflows as a means of integrating, processing, and analyzing data. Your first reference (currently cited in a rather different context) would provide a very good hook for this thriving topic that is all about sharing, reproducibility, and reusability of data processing and analysis methods. On the same lines, containerized computing (e.g., Docker) is only very briefly metioned. Even more than with data, using technologies such as these is crucial for ensuring reproducibility over longer periods of time (when software versions of dependencies have changed, webservices have become unavailable, and so forth).

The section "What can the research community do to encourage best practice?" gives a rather remote, high level view that addresses several different institutional entities - except for the individual researcher within the target audience who actually has to follow the discussed best practices to enable the data life cycle.

Additionally, here are some suggestions for increasing the usefulness and potential impact of the article within the current target audience, and possibly beyond: 
Important interdependecies between the different steps of the life cycle could be mentioned. For instance, the choice of which ontologies to use for metadata and data in the collection step will necessarily be influenced by a) the ontologies used in the data found in public repositiories and reused in the current experiment, b) the ontologies mandated by the repositories the data product is to be published in, and c) the ontologies required and used by the (third party, reused) software applied in the processing of the data. These interdependencies often not only put a limit to the choices available regarding the ontologies to be used but also raise a barrier when conversion and mapping between different ontologies is necessary between steps in the life cycle.

The topic of data privacy is only very briefly touched but fundamental when it comes to sharing and publishing data. It may be out of scope of this article, but a slightly more thorough discussion of the issue would to its importance more justice, I feel.

An additional figure that maps the best practices enumerated in the text to the rather coarse life cycle shown in Figure 1 could prove highly instructive. Something like a 'data life cycle best practices cheat sheet' ;)

If you (the authors) have any questions regarding this review, please do not hesitate to contact me.

Is the topic of the opinion article discussed accurately in the context of the current literature?

Yes

Are all factual statements correct and adequately supported by citations?

Yes

Are arguments sufficiently supported by evidence from the published literature? Yes

Are the conclusions drawn balanced and justified on the basis of the presented arguments? Yes

Competing Interests: No competing interests were disclosed.

Reviewer Expertise: Biomedical knowledge management, systems architectures, clinical informatics

I confirm that I have read this submission and believe that I have an appropriate level of expertise to confirm that it is of an acceptable scientific standard, however I have significant reservations, as outlined above.

Reader Comment 27 May 2018

Pip Griffin 


\section{Response to Review 2}

We thank Dr. Starlinger for his review and respond to his comments below (reviewer comments in italics, our responses in plain text).

The article gives a brief overview of the data life cycle in the life sciences and offers an entry point for accessing relevant information about current approaches to increasing compliance with the FAIR data sharing principles at each step of this life cycle. It expressly targets "life science researchers wanting to improve their data management practice" and is labeled as an Opinion article.

The article is well written and comfortable to read, and the concise presentation follows a clear structure. While to me as a biomedical data researcher, who may not strictly belong to the target audience, the article provided only little additional insight, I can well see how - as an entry point the article provides valuable information to its target audience.

Thank you.

That said, I believe the article needs clarification and some extension in a few places: The list of authors is quite extensive. Please clarify the roles of the authors in conception/conduction/preparation of the manuscript.

The authorship roles are described in the 'Author Details' section using the F1000Research authorship classification scheme. To give a bit more detail, Maria Victoria Schneider and Philippa Griffin conceptualised the paper as a follow-up to the Data Life Cycle workshop series run by EMBL Australia Bioinformatics Resource (EMBL-ABR) in October 2016. Jyoti Khadake, Suzanna Lewis, Sandra Orchard, Andrew Pask, Bernard Pope, Ute Roessner, and Torsten Seemann were workshop faculty who presented sessions and led group discussions. Jeffrey Christiansen, Sonika Tyagi, Nathan Watson-Haigh, Saravanan Dayalan and Simon Gladman have Key Area Coordinator roles with EMBL-ABR. All other authors were workshop attendees who subsequently volunteered to contribute to the manuscript. Philippa Griffin drafted the manuscript with input and supervision from Maria Victoria Schneider. All authors then had the opportunity to edit and comment on the text, figures and tables (via a shared Google Doc) and did so through several revisions of the manuscript.

How exactly does the proposed data life cycle differ from related (cited) suggestions, and why? How is it 'aimed at life science researchers specifically'? (Introduction)

This data life cycle is rather similar to others but we see it as having some important practical differences that make it more relevant to life science researchers, as follows:

The USGS data life cycle model does not include distinct steps for finding existing data and collecting new data (both are implied under 'acquire'), whereas in the life sciences these two steps are performed differently, with different limitations and considerations and so we see the need for highlighting both. As Dr. Nahnsen (the other reviewer) has noted, the integration of existing and new data can also be very complex in the life sciences and so deserves a place in the data life cycle diagram (it does not occur in the USGS model). Finally, 
we have separated the 'publish' and 'share' steps since publishing manuscripts and sharing data are highly distinct in the minds of most life science researchers due to the publicationfocussed way the world of life science research currently operates. Each has different actions relevant to good practice data management.

The DataOne data life cycle model has a heavier focus on data collection, with distinct steps for 'collect', 'assure', and 'describe'. We would argue that data quality assurance is generally considered an intrinsic part of data collection in the life sciences and does not require its own step. We also consider 'description' as part of the collection step as this should be done at the same time (or ideally planned beforehand), and we cover this in the article with the sections on metadata. This model also lacks the Publishing and Sharing steps ('sharing' is subsumed with 'storing' under 'preserve') which we believe are important, distinct considerations for life science researchers as mentioned above. The Digital Curation Centre data lifecycle model is similar to the DataOne model.

The tabular overviews of existing resources are a nice asset but they are, of course, not exhaustive. Please clarify how the selections of databases/registries, tools, ontologies etc were made for inclusion in the article - and possibly state where to find more complete lists of resources for the life sciences.

These tables are intended to demonstrate the scope of the resources available and indeed are not exhaustive. The databases/registries, standards and ontologies presented were 'crowd-sourced' from the authors' suggestions, in an attempt to present the most relevant options for resources used across the wide range of biology sub-domains this group of authors represents. We have now referenced FAIRsharing.org in the caption of the databases/registries and standards tables (Tables 1, 3 and 4), as this website contains more complete, maintained lists of resources.

The integrating step of the life cycle has no description in the article - even though this is a very intricate step that often has great influence when collecting data (e.g., the choice of ontologies to use for describing collected data and metadata will often depend on the ontologies used in re-used (found) data), and, even more, is at the core of making datasets interoperable, i.e., making them integratable with newly collected data.

We have now changed the title of the Processing and Analysing Data section to Integrating, processing and analysing data to ensure this step is highlighted. The point about integration having great influence on the data collection and processing strategy is indeed important and we have now included a paragraph dealing with this explicitly (Integrating, Processing and Analysing Data section, para 1).

In the processing step, you make no mention of Scientific Workflows as a means of integrating, processing, and analyzing data. Your first reference (currently cited in a rather different context) would provide a very good hook for this thriving topic that is all about sharing, reproducibility, and reusability of data processing and analysis methods. On the same lines, containerized computing (e.g., Docker) is only very briefly metioned. Even more than with data, using technologies such as these is crucial for ensuring reproducibility over longer periods of time (when software versions of dependencies have changed, web- 
services have become unavailable, and so forth).

We agree this is an active and important area of development in the research reproducibility field. We have now expanded the Integrating, Processing and Analysing Data section (para 2) to include mention of scientific workflows, workflow repositories and containerized computing.

The section "What can the research community do to encourage best practice?" gives a rather remote, high level view that addresses several different institutional entities - except for the individual researcher within the target audience who actually has to follow the discussed best practices to enable the data life cycle.

Thanks for pointing this out - we have now added three recommendations for individual researchers at the start of this section as follows:

\section{Researchers reusing any data should openly acknowledge this fact and fully cite the dataset, including unique identifiers.}

2. Researchers should endeavour to improve their own data management practices in line with best practice in their subdomain - even incremental improvement is better than none!

3. Researchers should provide feedback to their local institution, data repositories and bodies responsible for community resources (data formats, controlled vocabularies etc.) where they identify roadblocks to good data management.

Additionally, here are some suggestions for increasing the usefulness and potential impact of the article within the current target audience, and possibly beyond:

Important interdependecies between the different steps of the life cycle could be mentioned. For instance, the choice of which ontologies to use for metadata and data in the collection step will necessarily be influenced by a) the ontologies used in the data found in public repositiories and reused in the current experiment, b) the ontologies mandated by the repositories the data product is to be published in, and c) the ontologies required and used by the (third party, reused) software applied in the processing of the data. These interdependencies often not only put a limit to the choices available regarding the ontologies to be used but also raise a barrier when conversion and mapping between different ontologies is necessary between steps in the life cycle.

At the risk of making the paper too long, we agree it is important to point out the complexities and interdependencies that can be involved in good data management practice (this actually helps explain why it is implemented rather haphazardly at present). We have now included a flow-chart (Figure 2) as a guide to how a researcher might actually use a data life cycle approach. It is still rather high-level but shows how downstream requirements influence choices made at each stage of a research project.

The topic of data privacy is only very briefly touched but fundamental when it comes to sharing and publishing data. It may be out of scope of this article, but a slightly more 
thorough discussion of the issue would to its importance more justice, I feel.

We agree that data privacy is fundamental for research involving human data and have now expanded the text in the Finding Data section (para 3), the Storing Data section (para 1) and the Sharing Data section (para 1) to make it clear to readers that for human data, much extra planning and effort is typically required to deal with these considerations.

An additional figure that maps the best practices enumerated in the text to the rather coarse life cycle shown in Figure 1 could prove highly instructive. Something like a 'data life cycle best practices cheat sheet' ;)

We are concerned a generic 'cheat sheet' would not incorporate enough subdomain-specific detail to be of practical use. Instead, we've included a 'flow chart' figure (now Figure 2) to demonstrate an example of how a researcher might work through the data life cycle including feedback loops that show the need for prior planning.

If you (the authors) have any questions regarding this review, please do not hesitate to contact me.

Competing Interests: No competing interests were disclosed.

The benefits of publishing with F1000Research:

- Your article is published within days, with no editorial bias

- You can publish traditional articles, null/negative results, case reports, data notes and more

- The peer review process is transparent and collaborative

- Your article is indexed in PubMed after passing peer review

- Dedicated customer support at every stage

For pre-submission enquiries, contact research@f1000.com 